\title{
Oxido nítrico: inibição das plaquetas e participação na formação do trombo
}

\author{
Nitric oxide: inhibition of platelets and participation in thrombus formation
}

Denise Siqueira Vanni'; Bruno Horstmann²; Alexandre Miguel Benjo'; João Paulo Lima Daher; Salim Kanaan'; Marcos Sleiman ${ }^{6}$

\begin{tabular}{l|l}
\multicolumn{1}{c|}{ Unitermos } & resumo \\
\hline Óxido nítrico & $\begin{array}{l}\text { Neste artigo faremos uma revisão bibliográfica de modo que entendamos como o óxido nítrico (NO) } \\
\text { atua sobre as plaquetas, compreendendo assim mais um mecanismo antiplaquetário. Nos últimos } 25 \\
\text { anos a função do NO na biologia evoluiu do seu reconhecimento como poluente ambiental para subs- } \\
\text { Trombo }\end{array}$ \\
$\begin{array}{l}\text { tância endógena envolvida em comunicação intracelular e intercelular e na transdução de sinais. O NO } \\
\text { é uma molécula polivalente que exerce um papel na regulação da hemostasia, sendo responsável pela } \\
\text { inibição das plaquetas em todos os seus níveis de atuação, desde adesão até agregação, impedindo, } \\
\text { dessa forma, posterior formação de trombo. Inúmeras desordens clínicas têm sido reportadas em que } \\
\text { a insuficiência da produção de NO endógeno e, portanto, a ausência de inibição de ação plaquetária, } \\
\text { parece contribuir para os eventos trombóticos. }\end{array}$
\end{tabular}

abstract

In this article we make a review above the way that nitric oxide (NO) influence platelets over the past 25 years. The role of NO in biology has evolved from being recognized as an environmental pollutant to an endogenously produced substance involved in intracellular and intercellular communication and signal transduction. NO is a multifunctional molecule that plays a role in the regulation of hemostasis. It is responsible for platelets inhibition in all levels of its action, from adhesion to aggregation, preventing in this manner, thrombus formation. Several clinical disorders have been reported in which endogenous NO production insufficiency and, as a consequence, the absence of platelets action inhibition, seems to contribute to thrombotic events. key words

Nitric oxide

Platelets

Thrombus

\section{Introdução}

A descoberta das funções biológicas do óxido nítrico (NO) na década de noventa foi uma completa surpresa. Em 1992, o NO foi chamado "a molécula do ano" pela revista Science, uma sociedade do óxido nítrico foi fundada e uma revista científica devotada inteiramente ao NO foi criada. O Prêmio Nobel em Fisiologia ou Medicina, em 1998, foi dado a Ferid Murad, Robert F. Furchgott e Louis J. Ignarro pela descoberta das propriedades de sinalização do $\mathrm{NO}^{(2)}$.
Nos últimos 25 anos, a função do NO na biologia evoluiu do seu reconhecimento como poluente ambiental para substância endógena envolvida em comunicação intracelular e intercelular e na transdução de sinais ${ }^{(5)}$.

O NO é produzido por uma família de enzimas chamadas óxido nítrico sintases, localizadas numa variedade de tipos celulares, desde o endotélio vascular até os neurônios. Os seus efeitos biológicos são iniciados através da ativação da enzima heterodimérica guanilil ciclase solúvel (GCS) e/ou através de outras reações químicas $^{(2)}$.

\footnotetext{
1. Médica residente em Clínica Médica do Hospital Santa Marcelina (HSM).

2. Médico pós-graduando em Análises Clínicas do Departamento de Patologia da Universidade Federal Fluminense (UFF).

3. Pós-Doutorado no Johns Hopkins University, Baltimore, Maryland (EUA).

4. Mestrando do Programa de Pós-graduação em Patologia da UFF; estagiário no lohns Hopkins Hospital, Baltimore, Maryland (EUA).

5. Médico patologista clínico; mestre em Biofísica pela Universidade Federal do Rio de Janeiro (UFR)); especialista em Patologia Clínica pela Sociedade Brasileira de Patologia Clínica (SBPC); professor-adjunto da disciplina de Bioquímica Clínica da UFF; coordenador da residência médica e do internato em Patologia Clínica da UFF.

Trabalho realizado no Departamento de Patologia da UFF.

6. Doutorado em Cardiologia no Instituto do Coração (Incor) da Faculdade de Medicina da Universidade de São Paulo (FMUSP).
} 
A ativação de GCs resulta na produção de guanosina monofosfato cíclico (GMPc), um segundo mensageiro que promove várias mudanças fisiológicas no organismo humano. O NO também pode mediar mudanças fisiológicas por meio de modificações de proteínas celulares, como a nitração de tirosina ${ }^{(4)}$.

É uma molécula polivalente que exerce um papel na regulação da hemostasia. É responsável pela inibição das plaquetas em todos os seus níveis de atuação (desde adesão até agregação), impedindo, dessa forma, posterior formação de trombo.

A maioria dos mecanismos de ação do NO sobre as plaquetas é mediada pelo segundo mensageiro GMPc. No entanto, já há evidências de mecanismos independentes do GMPc que estão sendo mais bem elucidados nesses últimos anos ${ }^{(11)}$. Portanto, o NO representa, por intermédio de sua influência sobre as plaquetas, importante papel na regulação da formação de trombo no organismo humano. Assim, desordens clínicas têm sido reportadas em que a insuficiência da produção de NO endógeno e, conseqüentemente, a ausência de inibição de ação plaquetária, parece contribuir para eventos trombóticos, em condições como síndromes coronarianas agudas, fibrilação atrial, pré-eclâmpsia, síndrome hemolítico-urêmica e púrpura trombocitopênica trombótica.

Dessa forma, ao entender como o NO atua sobre as plaquetas, podemos entender melhor mais um mecanismo antiplaquetário e assim abrir portas à descoberta de uma nova forma de intervenção na formação de trombos.

\section{Óxido nítrico}

O NO foi identificado como importante molécula sinalizadora no organismo dos humanos em 1987, quando se descobriu que o fator relaxante derivado do endotélio (FRDE), um vasodilatador endógeno produzido pelos vasos sangüíneos, era, na verdade, o próprio NO. Ele é um gás relativamente estável e altamente lipofílico, que pode se difundir livremente por meio da membrana de suas células-alvo, e apresenta meiavida muito curta após ser liberado na corrente sangüínea ${ }^{(3)}$. É considerado um radical livre, ou seja, uma molécula que apresenta um elétron não-emparelhado no orbital externo, 0 que o torna muito reativo a qualquer outro tipo de molécula, incluindo lipídios, proteínas e ácidos nucléicos.

O NO é reconhecido no organismo humano por suas variadas funções fisiológicas que abrangem os sistemas cardiovascular, imune, reprodutivo e nervoso, bem como pelo seu papel na hemostasia, configurando a esse mediador gasoso um primordial valor para o funcionamento normal do organismo.

\section{Síntese}

O NO é produzido por meio da ação da enzima chamada óxido nítrico sintase (NOS). Essa catalisa a formação de L-citrulina e NO a partir da L-arginina, utilizando o oxigênio e a nicotinamida adenina dinucleotídeo fosfato (NADPH) como co-substratos, e flavina mononucleotídeo (FMN), flavina adenina dinucleotídeo (FAD), tetraidrobiopterina (BH4), heme, $\mathrm{Ca}^{2+} / \mathrm{calmodulina}$ e possivelmente zinco, como co-fatores (Figura 1).

Existem três isoformas de NOS em nosso organismo: NOS endotelial (eNOS ou NOS III), NOS neuronal (nNOS ou NOS I) e NOS induzida (iNOS ou NOS II). As duas primeiras são também conhecidas como NOS constitutivas (cNOS), visto que são expressas de forma constitutiva nas células endoteliais e neuronais. Essas NOS são reguladas pelo complexo de $\mathrm{Ca}^{2+}$-calmodulina ( $\mathrm{Ca}^{2+}$-dependentes) e produzem o NO por pouco tempo (segundos até minutos) em pequena quantidade. Já a iNOS, como o próprio nome indica, é induzida e regulada independente do $\mathrm{Ca}^{2+}$,

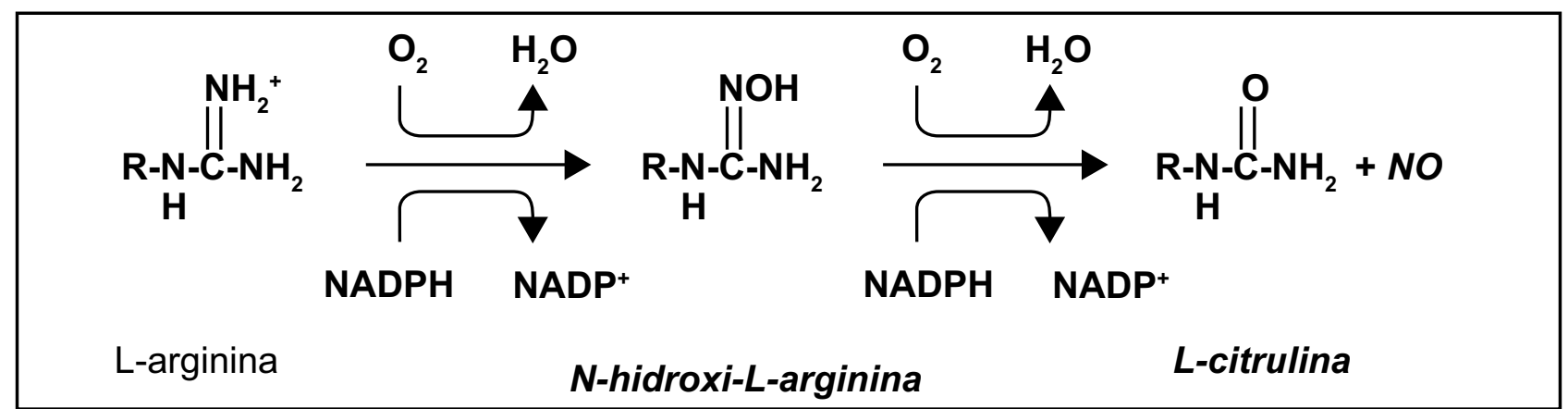

Figura 1 - Síntese de óxido nítrico (NO) pela óxido nítrico sintase (NOS)

Fonte: STANKEVICIUS, E. et al. Role of nitric oxide and other endothelium-derived factors. Med, v. 39, p. 4, 2003. 
produzindo NO por longo tempo (horas a dias) em maior quantidade(2).

A eNOS é ativada por pequeno estresse na interface célula endotelial e pelo sangue, produzindo NO que se difunde para fora do lúmen do vaso para relaxar o músculo liso da vasculatura e/ou para dentro do lúmen, no qual age inibindo a agregação plaquetária e a adesão de leucócitos na parede dos vasos. A eNOS tem sido encontrada em outras células além das endoteliais, como linfócitos $T$, plaquetas, eritrócitos e cardiomiócitos.

A nNOS produz NO como neurotrasmissor e é muito encontrada em neurônios, mas também em mastócitos, plaquetas e, possivelmente, em neutrófilos.

Em relação a sua síntese, a iNOS é induzida por vários mecanismos, particularmente os relacionados a citocinas inflamatórias, como interferon gama, interleucina-1 (IL-1) e fator de necrose tumoral alfa (TNF- $\alpha$ ). Esta é encontrada em macrófagos, neutrófilos e plaquetas.

\section{Funções gerais}

Como já mencionado, o NO apresenta funções nos sistemas cardiovascular, nervoso, reprodutor, imune e no processo de hemostasia. Existem múltiplas vias utilizadas pelo NO para promover suas ações, que dependem do meio e da quantidade de NO produzido( ${ }^{(5)}$.

Há, portanto, os efeitos relacionados à baixa concentração de NO, ou seja, que equivale a menos do que $1 \mu \mathrm{M}$ dessa molécula e os relacionados à alta concentração de $\mathrm{NO}$, se referindo a mais do que $1 \mu \mathrm{M}$ (Figura 2$)^{(5)}$.
Entre os efeitos de baixa concentração de NO estão os de vários compostos, principalmente aqueles contendo metais de transição, e são divididos em quatro grupos:

- três grupos de fatores de transcrição que compreendem o grupo de componentes de ferro-tiol (Fe-S), do domínio ligante de zinco no DNA e do fator induzido por hipoxia (HIF-1), que é um fator angiogênico;

- um grupo de enzimas contendo heme que inclui a hemeoxigenase 1 (HO-1), o citocromo $\mathrm{C}$ oxidase, a catalase e a guanilil ciclase solúvel (GCs) ${ }^{(5)}$.

Os efeitos da elevada concentração de NO incluem nitrosilação, em que os nitrosotióis de cisteínas são formados - esse fenômeno apresenta efeito sobre as funções de várias proteínas -, e nitração de tirosina, esta dependendo tanto da concentração de NO quanto da existência de oxidantes fortes no meio, como radical superóxido $\left(\mathrm{O}^{2-}\right)^{(5)}$.

Apesar de todos esses diferentes mecanismos de ação mencionados, o NO exerce todas as suas ações, principalmente através da ativação da enzima GCs. Esta produz o segundo mensageiro $3^{\prime} 5^{\prime}$ guanosina monofosfato cíclico (GMPc) que iniciará assim as cascatas bioquímicas de sinalização nas diversas células-alvo. Estas últimas estão localizadas em diversos sistemas no organismo humano, contudo a atuação do NO em cada um deles será comentada a seguir.

Em relação ao sistema cardiovascular, o NO desempenha importante papel no controle do tônus vascular, por meio do relaxamento da musculatura lisa dos vasos, promovendo assim a dilatação vascular. É nesse efeito do NO que se baseia o mecanismo de ação de drogas, como a nitroglicerina, por exemplo ${ }^{(15)}$.

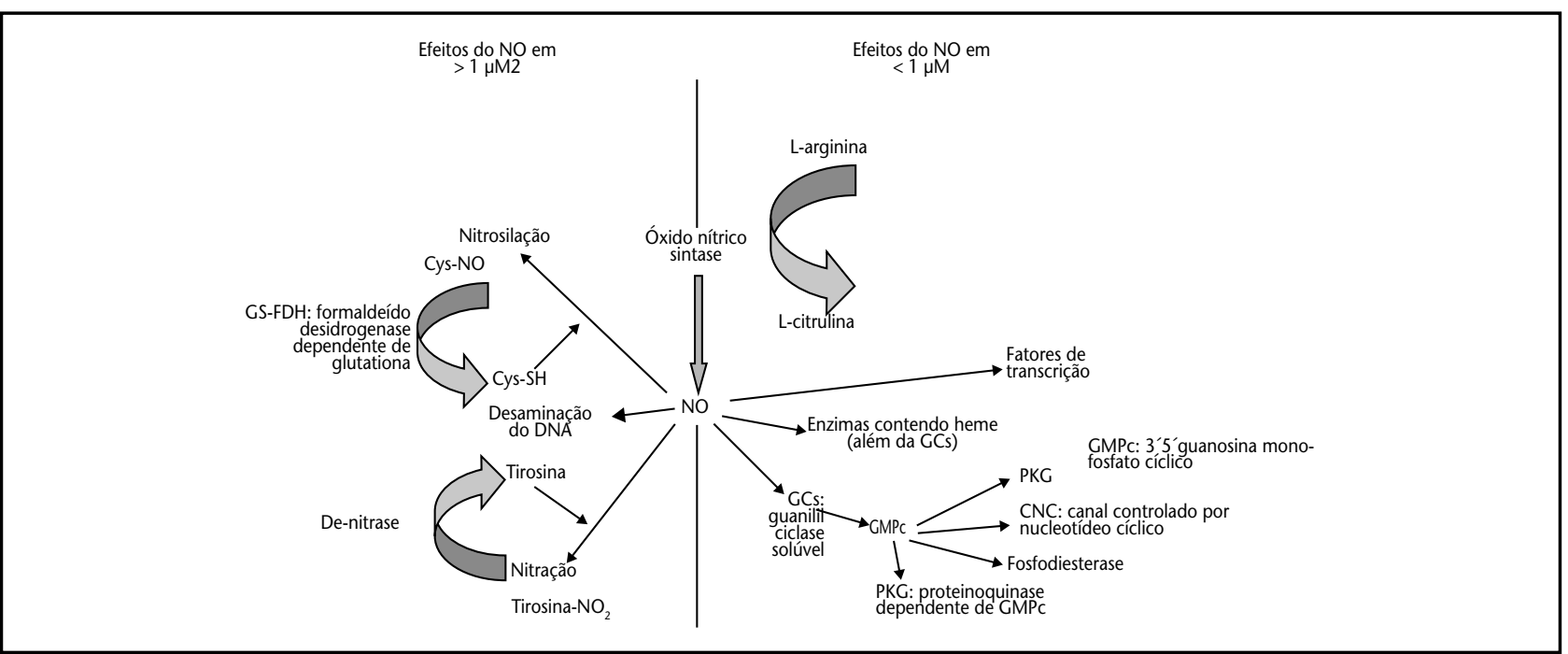

Figura 2 - Vias utilizadas pelo óxido nítrico (NO) de acordo com sua concentração

Fonte: HANAFY, K.A. et al. NO, nitrotyrosine, and cyclic CMP in signal transduction. Med Sci Monit, v. 7, n. 4, 801-19, 2001. 
Atua também como neurotransmissor no sistema nervoso, promovendo a sinalização entre as células nervosas, estando associado a processos de aprendizado, memória, sono, dor e provavelmente depressão ${ }^{(15)}$.

Em relação ao sistema reprodutor, atua no desenvolvimento e manutenção da ereção. O NO promove o relaxamento das células musculares lisas localizadas em torno dos vasos que suprem o espaço cavernoso, permitindo, desse modo, mais fluxo sangüíneo nesses vasos e, portanto, a ereção. $O$ citrato de sildenafil potencializa esse efeito promovido pelo $\mathrm{NO}^{(11,15)}$.

Assim, considerando sua função no sistema imunológico, esse mediador gasoso exerce importante papel em vários aspectos da resposta inflamatória, além de atuar no endotélio, promovendo dilatação vascular, um dos sinais cardinais da inflamação. No caso da sepse, por exemplo, contribui para a vasodilatação que resulta em choque séptico. Ele também diminui a permeabilidade endotelial, e esse fato foi demonstrado em vários modelos experimentais ${ }^{(13)}$.

O NO interfere na atuação dos leucócitos na inflamação e promove a modulação da expressão de P-selectina (proteína de adesão) produzida no endotélio, reduzindo, dessa maneira, a adesão de leucócitos à parede vascular ${ }^{(13)}$, bem como promove a diminuição da agregação de neutrófilos e de sua secreção.

Os mastócitos têm um importante papel no processo inflamatório. A reatividade desses é regulada por seu próprio $\mathrm{NO}$ e/ou de outra célula. O mediador produzido pelos mastócitos parece modular a liberação de mediadores inflamatórios dos mesmos, incluindo a histamina, o fator ativador plaquetário (FAP) e o fator de necrose tumoral (TNF), e também promove a diminuição da propensão de degranulação dos mastócitos.

Nos macrófagos, o NO inibe a produção de uma variedade de citocinas imunomoduladoras, bem como modula a ação dessas mesmas sobre as células-alvo.

Considerando as plaquetas, essas exercem importante papel nos processos de inflamação, de coagulação e de trombose. O NO atua sobre as plaquetas inibindo os três componentes de sua função: adesão, ativação e agregação, assim como o recrutamento plaquetário ${ }^{(4)}$, interferindo, portanto, na inflamação e na hemostasia.

Visto que este trabalho tem seu enfoque no efeito inibitório do NO sobre as plaquetas, e no que isso interfere na patogênese do trombo, será abordado, adiante, o papel fisiológico das plaquetas no controle da hemostasia, o efeito inibitório do NO sobre essas e, conseqüentemente, na for- mação do trombo e, finalmente, as implicações decorrentes em diferentes desordens trombóticas.

\section{Plaquetas}

As plaquetas são pequenos fragmentos subcelulares que circulam no sangue com o formato de pequenos discos com dimensões de $0,5 \times 3,0 \mu \mathrm{m}$. Estão presentes em altas concentrações no sangue $\left(2-3 \times 10^{8} \mathrm{ml}^{-1}\right)$ e circulam no corpo humano durante sete dias ${ }^{(6)}$. Elas têm importante papel na prevenção do processo de sangramento dos vasos, participando da hemostasia primária, e também atuam nos processos imunes.

As plaquetas são formadas a partir dos prolongamentos citoplasmáticos dos megacariócitos, conhecidos como pró-plaquetas.

A formação das plaquetas pode ser dividida em duas fases:

- primeira fase: há proliferação nuclear e aumento do citoplasma do megacariócito, uma vez que este se encontra repleto de proteínas do citoesqueleto, grânulos e conteúdos granulares específicos das plaquetas e sistemas de membranas. Essa fase ocorre no período de dias e requer a indução pelo fator de crescimento específico de megacariócitos;

- segunda fase: ocorre o alongamento das pró-plaquetas (prolongamentos) e as plaquetas são liberadas. Essa fase é completada em horas ${ }^{(6)}$.

Na primeira fase os megacariócitos seguem um programa de maturação para juntar e liberar as plaquetas, contudo o resultado desse processo se acumula dentro do local do citoplasma dos megacariócitos que irá se converter em múltiplas pró-plaquetas. Com o tempo, na segunda fase, esses prolongamentos afinam e formam galhos repetidamente.

As plaquetas se formam nas extremidades das pró-plaquetas. À medida que as plaquetas formadas amadurecem, seu conteúdo composto de grânulos e organelas é entregue como uma corrente de partículas individuais, que se move do corpo celular do megacariócito para as extremidades da pró-plaqueta ${ }^{(6)}$. Após essa etapa, as plaquetas são liberadas na corrente sangüínea.

\section{Funções na hemostasia}

As plaquetas são responsáveis, conforme mencionado, pela hemostasia primária, um processo biológico que pára o sangramento decorrente de injúria vascular por meio da formação de um tampão plaquetário. 
Para exercer esse papel, é necessária a integridade de três componentes da função plaquetária: adesão, atividade e agregação (Figura 3).

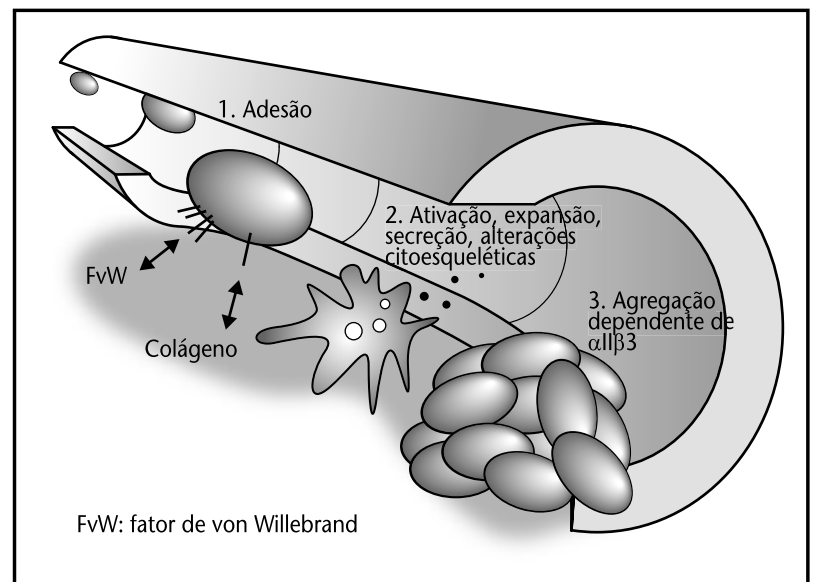

Figura 3 - Os três componentes da função plaquetária (adesão, ativação e agregação) Fonte: YIP, J. et al. Primary platelets adhesion receptors. IUBMB Life, v. 57, n. 2, p. 103-8, 2005.

O início de todo esse processo ocorre quando há injúria vascular, com conseqüente exposição do colágeno subendotelial às plaquetas circulantes no plasma. Inicia então a fase de adesão mediada por receptores de adesão plaquetários primários, sendo esses: a glicoproteína VI (GPVI) e o complexo glicoproteína Ib-IX-V (GPIb-IX-V). A primeira se liga ao colágeno e às proteínas do colágeno de ligação cruzada, e a segunda se liga ao fator de von Willebrand (FvW), às integrinas leucocitárias $\alpha \mathrm{M} \beta 2$ e à P-selectina, que é um receptor de membrana expresso na superfície das plaquetas ativadas ou nas células endoteliais ativadas ${ }^{(16)}$.

As ligações da GPVI com o colágeno e do complexo GPIb-IX-V com o FvW exercem aumento de expressão das integrinas plaquetárias, incluindo integrinas $\alpha 2 \beta 1$ que se ligam ao colágeno, e integrinas $\alpha$ llb $\beta 3$ que se ligam ao fibrinogênio ou ao FvW, mediando a agregação plaquetária (Figura 4) $^{(16)}$.

Uma vez a plaqueta aderida, ela sofre a ação de agonistas plaquetários, incluindo o próprio colágeno, a trombina e a epinefrina, que darão início à ativação das plaquetas. Esses agonistas se ligam a receptores de membrana das plaquetas e ativam cascatas bioquímicas no citosol.

Uma dessas cascatas se inicia pela estimulação da fosfolipase $C$, que hidrolisa o fosfatidilinositol $3^{\prime} 4^{\prime}$ difosfato (PIP2) para formar inositol trifosfato (IP3) e diacilglicerol (DAG). O IP3 se liga aos receptores no principal sítio de armazenamento de cálcio $\left(\mathrm{Ca}^{2+}\right)$ - o sistema tubular denso - iniciando o efluxo de $\mathrm{Ca}^{2+}$ de dentro desse para o citosol e, assim, elevando a concentração intracelular de $\mathrm{Ca}^{2+}$. Esse $\mathrm{Ca}^{2+}$ promove então a liberação dos componentes dos grânulos intracelulares, como também se associa à calmodulina, promovendo o rearranjo na estrutura do citoesqueleto e modificando sua forma com emissão de prolongamentos.

O DAG ativa a proteinoquinase $C$ (PKC) que, assim como o IP3, induz a liberação dos componentes dos grânulos intracelulares e promove a ativação do receptor de membrana glicoproteína Ilb/llla (GPllb/Illa) que, junto com o fibrinogênio, é responsável pela agregação plaquetária( ${ }^{(8)}$.

Esses grânulos plaquetários intracelulares são de dois tipos: grânulos alfa e grânulos densos. Os primeiros liberam como componentes FvW, trombospondina, plasminogênio, fibronectina e P-selectina que, uma vez liberados, aumentam os processos adesivos enquanto promovem interação entre as células. Os últimos liberam serotonina e adenina difosfato (ADP), que promovem o recrutamento de outras plaquetas para o tampão plaquetário em crescimento via interação ligante-receptor específico na superfície das plaquetas.

A ligação do ADP liberado ao receptor purinérgico das plaquetas, e dos outros agonistas já mencionados a seus receptores, promove ativação da cascata da proteinoquinase de ativação mitogênica (MAPquinase) levando à estimulação da fosfolipase A2 (PLA2) que hidrolisa a fosfatidilcolina $(\mathrm{FC})$, liberando o ácido araquidônico (AA). Este último tem como um de seus produtos o tromboxano A2 (TXA2), um potente agonista plaquetário e vasoconstritor. A MAPquina-

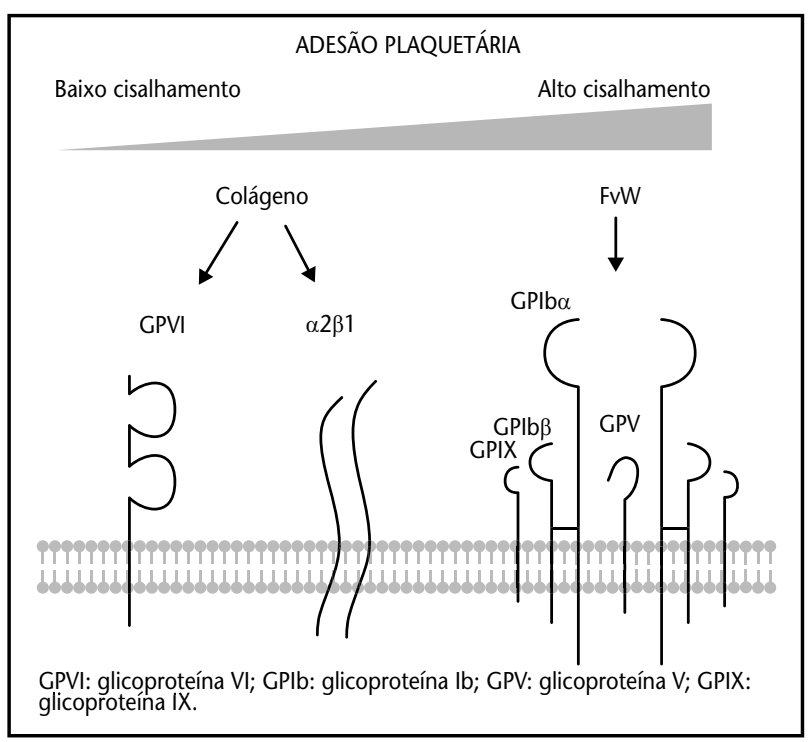

Figura 4 - Receptores de adesão plaquetária

Fonte: YIP, J. et al. Primary platelets adhesion receptors. IUBMB Life, v. 57, n. 2, p. 103-8, 2005. 
se também promove liberação de $\mathrm{Ca}^{2+}$ do sistema tubular denso para o citosol( ${ }^{(8)}$.

Uma vez ativado o receptor GPIllb/llla, esse muda sua conformação, passando a interagir fortemente com o fibrinogênio que se encontra solúvel no plasma, com o qual medeia o processo de agregação e, conseqüentemente, a formação do tampão plaquetário.

\section{Funções do óxido nítrico nas plaquetas}

Como já mencionado, o NO tem diversas funções no nosso organismo, sendo uma delas, a inibição da adesão, ativação, agregação e recrutamento plaquetários ${ }^{(1,4)}$. Tanto o NO derivado do endotélio quanto o derivado das próprias plaquetas têm esse papel, inibindo, portanto, a propagação da formação de trombo.

O NO exerce sua ação inibitória sobre as plaquetas mediante vias GMPc dependentes (já bem conhecidas) e por vias GMPc independentes (bem menos caracterizadas).

O segundo mensageiro (GMPc), principal via de atuação do NO, é originado a partir de 5 trifosfato de guanosina (GTP) pela ação da GCs no citosol estimulada pelo NO.

Os vários mecanismos exercidos pelo NO sobre as plaquetas dependentes dessa via GMP cíclica são:

- redução do nível de $\mathrm{Ca}^{2+}$ citoplasmático;

- bloqueio do receptor de TXA2;

- modulação da expressão de P-selectina;

- modulação da ligação de fibrinogênio via receptor GPIIb/ Illa (Figura 5) ${ }^{(8)}$.

A redução do nível de $\mathrm{Ca}^{2+}$ intracelular ocorre pela inibição de liberação de $\mathrm{Ca}^{2+}$ via receptor do sistema tubular denso, do aumento da taxa de extrusão de $\mathrm{Ca}^{2+} \mathrm{e}$ da redução de entrada de $\mathrm{Ca}^{2+}$ do meio extracelular. Além disso, o NO aumenta a atividade da $\mathrm{Ca}^{2+}$-adenina trifosfatase (ATPase) do retículo sarcoplasmático, que resulta em menores níveis de $\mathrm{Ca}^{2+}$ disponíveis para os mecanismos de ativação e agregação.

O NO catalisa a fosforilação do receptor de TXA2, evitando assim a ativação plaquetária mediada por esse último.

A expressão da P-selectina, como já mencionado, é necessária para facilitar a adesão plaquetária. O NO induz a diminuição dessa proteína, promovendo dessa forma a inibição da adesão.

Há redução do número total de receptores GPIlb/Illa na superfície da plaqueta e aumento da constante de dissociação desse receptor pelo fibrinogênio, criando, então, condições desfavoráveis para a agregação plaquetária.

Este mesmo NO também se difunde pela membrana da plaqueta, passando a exercer suas várias ações nas plaquetas vizinhas.

Em relação aos mecanismos exercidos pelo NO independente do GMPc, foi observado no estudo de Gordge et al., em 1998, e Tsikas et al., em 1999, que o bloqueio da via GMPc dependente não revoga totalmente a inibição da agregação plaquetária pelo NO, e outras vias possivelmente devem envolver nitrosilação de resíduos de tirosina via OONO- (peroxinitrito) ou inibição por meio da nitrosilação de proteínas da síntese de TXA2 ${ }^{(5,14)}$.

No estudo de Tsikas, em 1999, a S-nitroso-cisteína (SNC), um fator relaxante derivado do endotélio, inibiu potencialmente a agregação plaquetária induzida por colágeno e ácido araquidônico, e síntese de TXA2 nas plaquetas. A quinoxalin-1-one (ODQ), um inibidor seletivo da GCs inibiu a formação de GMPc induzida por SNC, mas não reverteu a inibição pela SNC sobre a agregação plaquetária induzida por colágeno e ácido araquidônico.

O estudo demonstrou que a SNC inibe a agregação plaquetária por mecanismos independentes de $\mathrm{GMPc}$, que podem envolver a inibição da síntese de TXA2 nas plaquetas de humanos ${ }^{(12)}$.

Outro estudo realizado por Localzo et al. mostrou que um fragmento nitrosilado do FvW inibe a agregação plaquetária. A relevância fisiológica desse achado aguarda posterior elucidação(14).

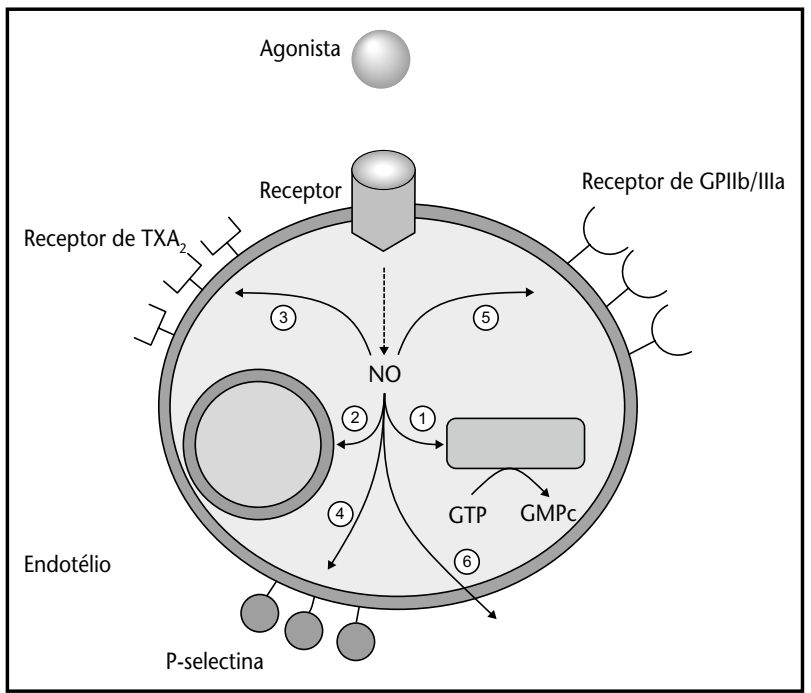

Figura 5 - Efeitos do óxido nítrico (NO) na inibição plaquetária via 3'5'guanosina monofosfato cíclico (GMPC)

Fonte: IIN, R.C. et al. Endogenous mechanisms of inhibition of platelet function. Microcirculation, v. 12, n. 3, p. 247-58, 2005. 
Beghetti et al., em 2003, mostraram que agregação in vitro é inibida se os estudos são feitos rápidos o suficiente, mas que níveis de GMPc intraplaquetários não estão elevados, indicando que um mecanismo GMPc independente possa estar envolvido( ${ }^{(5,14)}$.

Outros estudos demonstram que o NO, ainda por meio desse mecanismo independente de GMPc, ativa a ADPribosiltransferase e inibe a mobilização de $\mathrm{Ca}^{2+}$ no interior das plaquetas ${ }^{(5)}$.

Apesar de a maioria dos autores alegarem função inibitória do NO sobre as plaquetas, recentemente foi publicado um estudo de Marjanovic et al. nos EUA defendendo um novo conceito a respeito desse assunto( ${ }^{(9)}$. Eles demonstraram que a produção de pequena concentração de NO produzido por eNOS plaquetário estimula a secreção e agregação plaquetárias e, dessa forma, amplifica e estabiliza a agregação plaquetária.

Os resultados do estudo em que se baseou essa conclusão foram:

- plaquetas de ratos sem eNOS mostraram reduzida secreção e agregação plaquetárias em resposta a baixas concentrações de trombina, análogo de TXA2 (U46619) e colágeno;

- ratos sem eNOS mostraram reduzida habilidade de formar trombo arterial oclusivo em um modelo in vivo de trombose;

- inibidores de NOS reduziram a secreção e agregação plaquetárias;

- o substrato de NOS, L-arginina, que aumenta a produção de NO, também promoveu secreção e agregação plaquetárias.
Esses resultados parecem contradizer os resultados pregressos em que o NO teve o papel de inibir a ativação plaquetária. Todavia, há que se considerar que os estudos anteriores foram realizados em condições de elevada concentração de $\mathrm{NO}^{(9)}$.

Portanto, combinado com o achado desses estudos pregressos que demonstraram que elevadas concentrações de NO inibem a ativação plaquetária, os autores acreditam que seus resultados denotam um papel bifásico do NO na ativação plaquetária no qual, em baixa concentração desse, há um estímulo da ativação plaquetária, mas, em alta concentração, ocorre inibição dessa ativação.

\section{Insuficiência do óxido nítrico e desordens clínicas trombóticas}

O desenvolvimento de doenças trombóticas envolve injúria e/ou disfunção do vaso sangüíneo e ativação de plaquetas, como já mencionado. Mediante a exposição de agonistas, como a trombina, o ADP, o colágeno e o FvW, as plaquetas são ativadas e se agregam para formar o trombo primário. As plaquetas ativadas secretam enorme quantidade de ADP, serotonina e outros fatores que amplificam sua ativação e estabilizam o agregado. Também secretam fatores pró-coagulação, pró-inflamatórios e de crescimento. Logo, a ativação de plaquetas tem um importante papel não somente em tromboses arteriais agudas, mas também no desenvolvimento de doenças crônicas vasculares, como a aterosclerose, que por sua vez causa trombose ${ }^{(9)}$.

Diversas formas de desordens clínicas têm sido reportadas em que a insuficiência da produção de NO endógeno e, portanto, a ausência de inibição de ação plaquetária, parece contribuir para eventos trombóticos (Tabela) ${ }^{(4)}$.

\section{Tabela Desordens trombóticas associadas à deficiência de NO}

\section{Desordem trombótica}

Microangiopatia trombótica [39]

Síndrome hemolítico-urêmica

Púrpura trombocitopênica trombótica

Fibrilação atrial [36]

Sindromes coronarianas agudas [34]

Infarto agudo do miocárdio

Angina instável

Doença vascular aterotrombótica

Gravidez e pré-eclâmpsia [38]

Doença cerebrovascular tromboembólica pediátrica [57]

Fonte: Nitric oxide and its relationship to thrombotic disorders. I Thromb Haemost, 2003. 
Está bem estabelecido que a trombose é a causa de angina instável e de infarto agudo do miocárdio (IAM). Pacientes com essas síndromes coronarianas agudas possuem plaquetas ativadas que produzem muito menos $\mathrm{NO}$, quando em comparação com aqueles com doença coronariana estável. Essa redução na produção de NO é significativa, mesmo depois do controle de fatores de risco cardiovasculares e da extensão de doença aterosclerótica(4).

Essa observação sugere que o funcionamento irregular do NO derivado de plaquetas pode contribuir para o desenvolvimento de síndromes coronarianas agudas por meio de sua influência sobre a função e/ou recrutamento plaquetários e conseqüente formação de trombo.

Pacientes com fibrilação atrial (FA), uma condição associada com trombose intracardíaca aumentada e embolismo cerebral, têm níveis plasmáticos diminuídos de nitrito e nitrato, como também níveis reduzidos de GMPc plaquetário, sugerindo que deve haver níveis reduzidos de NO biodisponível nessa situação(4).

O mecanismo responsável pela redução dos níveis de NO associado à FA ainda não é conhecido. Todavia, condições de fluxo turbulento foram associadas à diminuição da atividade da NOS, provavelmente devido à injúria do endotélio.

A trombose também foi associada à deficiência de $\mathrm{NO}$ em desordens clínicas não-cardíacas. No entanto, em mulheres com pré-eclâmpsia, os níveis de GMPc estavam diminuídos.

Em pacientes com formas recorrentes de trombose microangiopática, incluindo síndrome hemolítico-urêmica e púrpura trombocitopênica trombótica, há evidências de que a lesão endotelial é uma característica crucial no desenvolvimento de trombose microvascular ${ }^{(4)}$. Os pacientes com essas doenças manifestam elevada concentração plasmática de metabólitos do $\mathrm{NO}$ e o soro desses pacientes aumenta a liberação de NO, quando incubados com culturas de células endoteliais.
De forma importante, a produção de superóxido e a peroxidação de lipídios também estão aumentadas, sugerindo que a interação dessas espécies de oxigênio reativo com o NO reduzem sua bioatividade por meio do aumento de seu estado oxidativo, levando potencialmente à formação de trombo(4).

\section{Conclusão}

O NO é uma molécula polivalente que exerce papel central na regulação da hemostasia.

A superfície íntima do endotélio vascular sadio é anticoagulante e antitrombótica, e secreta uma variedade de moléculas importantes para a regulação da função plaquetária e da coagulação sangüínea. A interação entre as plaquetas e as células endoteliais em sítios de injúria endotelial assegura a secreção de mediadores, como o NO, que previnem o crescimento intravascular do trombo.

O papel do NO na inibição plaquetária mediante, principalmente, GMPc já foi bem elucidado e novos estudos investigam outros mecanismos de ação dessa molécula. Recentemente, também surgiram novas frentes de pesquisa que contradizem essa função antitrombótica do NO, demonstrando, desse modo, como muito ainda precisa ser esclarecido sobre a atuação desse mediador gasoso na esfera da hemostasia.

No entanto, é importante frisar que essa função antitrombótica (defendida pela maioria dos estudos) abre portas para novas formas de medidas terapêuticas antiplaquetárias em futuro próximo.

O NO está envolvido numa variedade de vias biológicas, o que indica a sua importância na homeostase do organismo humano como um todo. Essa enorme variedade de funções só reforça ainda mais a necessidade de novos estudos para se tentar entender de forma mais completa a função do óxido nítrico no organismo.

\section{Referências}

I. ALONSO, DAVID; RADOMSKI, MAREK W. Nitric oxide, platelet function, myocardial infarction and reperfusion therapies. Heart Failure Reviews, v. 8, p. 47-54, 2003.

2. BIAN, K.; MURAD, F. Nitric oxide (NO ): biogeneration, regulation, and relevance to human diseases. Front Biosci, v. 8, p. d264-78, 2003

3. BOUCHER, J.L.; MOALI, C.; TENU, J.P. Nitric oxide biosynthesis, nitric oxide synthase inhibitors and arginase competition for L-arginine utilization. Cell Mol Life Sci, v. 55, p. I0I5-28, 1999.

4. BREDT,D.S.; SNYDER, S.H. Nitric oxide: a physiologic messenger molecule. Ann Rev Biochem, v. 63, p. 175-95, 1994.

5. EGBRINK, O. et al. Regulation of microvascular thromboembolism in vivo. Microcirculation, v. I2, n. 3, p. 287-300, 2005. 
6. FREEDMAN, J.E.; LOSCALZO, J. Nitric oxide and its relationship to thrombotic disorders. J Thromb Haemost, v. I, p. I I83-8, 2003.

7. HANAFY, K.A.; KRUMENACKER, J.S.; MURAD, F. NO, nitrotyrosine, and cyclicGMP in signal transduction. Med Sci Monit, v. 7, n. 4, 801-19, 2001.

8. HARTWIG, J.; ITALIANO JR., J.E. The Birth of the platelet. J Thromb Haemost, v. I, p. I580-6, 2003.

9. ITALIANO JR., J.E.; SHIVDASANI, R.A. Megakaryocytes and beyond: the birth of platelets. J Thromb Haemost, v. I, n. 6, p. II 174-82, 2003.

I0. JIN, R.C.; VOETSCH, B.; LOSCALZO, J. Endogenous mechanisms of inhibition of platelet function. Microcirculation, v. 12, n. 3, p. 247-58, 2005.

I I. JOHN, P. C.; VICTOR, J.D. Nitric oxide syntetase: role in the genesis of vascular disease. Ann Rev Med, v. 48, p. 489-509, 1997.

12. MARJANOVIC, J.A. et al. Stimulatory roles of nitric oxide synthase 3' and guanylyl cyclase in platelet activation. J Biol Chem, v. 280, n. 45, p. 37430-8, 2005.

13. MORREL, C.N. et al. Regulation of platelet granule exocytosis by S-nitrosylation. PNAS, v. I0, n. 102, p. 3782-7, 2005.

I4. STANKEVICIUS, E. et al. Role of nitric oxide and other endothelium-derived factors. Med, v. 39, p. 4, 2003.

I5.TSIKAS, D. et al. Inhibition of platelet aggregation by S-nitrosocysteine via cGMP-independent mechanisms: evidence of inhibition of thromboxane A2 synthesis in human blood platelets. FEBS Letters, v. 442, p. 162-6, 1999.

16.WALLACE,J.L. Nitric oxide as a regulator of inflammatory processes. Mem Inst Oswaldo Cruz, v. 100, supl. I, março 2005.

17.WALLIS, J.P. Nitric oxide and blood: a review. Transfusion Med, V. I5, p. I- II, 2005.

18. WIKIPEDIA. The free encyclopedia. Available at: www. wikipedia.org.

19. YIP, J. et al. Primary platelets adhesion receptors. IUBMB Life, v. 57, n. 2, p. 103-8, 2005 